\title{
Aktuelles 2014 zum DLT 2014 in Innsbruck
}

Mittlerweile sind die eingelangten Abstracts für unser Ende Oktober beginnendes DLT 2014 begutachtet und die Autoren über den Ausgang verständigt worden. Auch heuer sind wieder sehr spannende Vorträge und neuartige klinische Ansätze offeriert worden und werden auf dem Kongreß präsentiert. Zu einem besonderen Highlight können auch die Präsentationen der Poster werden, werden doch hier erstmals moderne E-Postersysteme zur Anwendung kommen, die eine sehr große Bildschirmfläche aufweisen und einem größeren Kreis von Interessierten eine Diskussion mit den Autoren vor dem Bildschirm ermöglichen.

Mehr Informationen hierzu und das aktuelle Vorprogramm finden Sie unter: www. ultraschall2014.at 